УДК 621.3

\author{
А. Я. Кулик, д.m.н., професор, \\ e-mail: kulyk@vnmu.edu.ua \\ Т. Г. Ревіна, \\ e-mail: tatiana@vnmu.edu.ua \\ М. В. Боднар, \\ e-mail: shargorod0523@gmail.com
}

Вінницький національний медичний університет ім. М. І. Пирогова, вул. Пирогова, 56, Вінниця, 21018, Україна

\title{
РЕССТРАЦІЯ І ОБРОБЛЮВАННЯ СИГНАЛУ ЕЕГ З ВИКОРИСТАННЯМ ПОЛІНОМІВ ЧЕБИШЕВА
}

При фізіологічних дослідженнях для оцінки активності головного мозку важливою умовою є зняття електроенцефалограми. У статті розглянуті питання побудови комп'ютерної системи для реєстрації ЕЕГ з використанням режиму переривань на рівні структури та алгоритмічного забезпечення. В залежності від методики реєстрації система містить від трьох до шістнадияти амплітудних вимірювальних каналів. Для відфільтровування високочастотних завад пропонується додаткова процедура цииррової фільтрачії з використанням поліномів Чебишева. Проведені розрахунки показали ї̈ ефективність. Пропонується методика оцінки мінімальної довжини реалізачії.

Ключові слова: електроенцефалограма, комп'ютерна система, цицрова фільтрація.

Актуальність. Головний мозок - найбільший орган центральної нервової системи. До нього входить близько 2600000 нервових волокон, а виходить близько 400000. Відповідно до приблизних оцінок мозок містить більше ніж $10^{13}$ нейронів, які забезпечують більше ніж $10^{16}$ взаємних сполучень [1 - 5]. Якщо припустити, що всі нейрони працюють паралельно, то на кожний з них припадає від 10000 до 100000 сполучень з іншими. Сумарна пропускна здатність нейронних мереж людського головного мозку складає $10^{14}$ $10^{16}$ біт/с, що набагато більше, ніж у сучасних комп'ютерах. Вважається, що один біт інформації проходить через $100-1000$ сенсорних каналів. Переважна частина цих шляхів може зникнути, перш ніж суттєво зменшиться кількість інформації, що приймається. Разом 3 тим, сенсорний рецептор може приймати лише до 10 біт/с. При цьому до свідомості людини попадає до 100 біт/с, а до пам'яті 1 біт/с. Центральна нервова система реалізує три можливі режими:

- збудження прийняте і відіслане;

- збудження прийняте і затримане;

- збудження прийняте і не відіслане.

Це суттєво зменшує кількість інформації, що оброблюється мозком.

При запам'ятовуванні нейронні системи грають важливу роль. 3 їх допомогою інфор- мація заноситься до пам'яті і зчитується з неї. Так само утворюються зв'язки при наявності нової інформації і вже існуючих знань.

Таким чином, важливою задачею $є$ формування нових підходів, методів і засобів реєстрації і оброблювання ЕКГ на базі останніх досягнень неврології та фізіології.

Розв'язання поставленої задачі. Існує декілька методик зняття ЕКГ (Кобба, Гібса тощо), які передбачають від трьох до шістнадцяти каналів реєстрації. Система розташування електродів «10/20» затверджена Міжнародною федерацією клінічної електроенцилографії та нейрофізіології.

Принципи побудови мікроелектронних систем достатньо докладно описані в літературі [6 - 8].

Особливості реєстрації зумовлюють певні особливості побудови мікропроцесорної системи:

реєстрація динамічних характеристик визначає необхідність побудови незалежних каналів без їх комутації, хоча це суттєво збільшує витрати на апаратне і програмне забезпечення;

в велика кількість каналів передбачає режим реєстрації в режимі переривань (програмно-апаратно) [9].

Структура комп'ютерної системи для реєстрації ЕКГ наведена на рис. 1, а процедура - на рис. 2. 


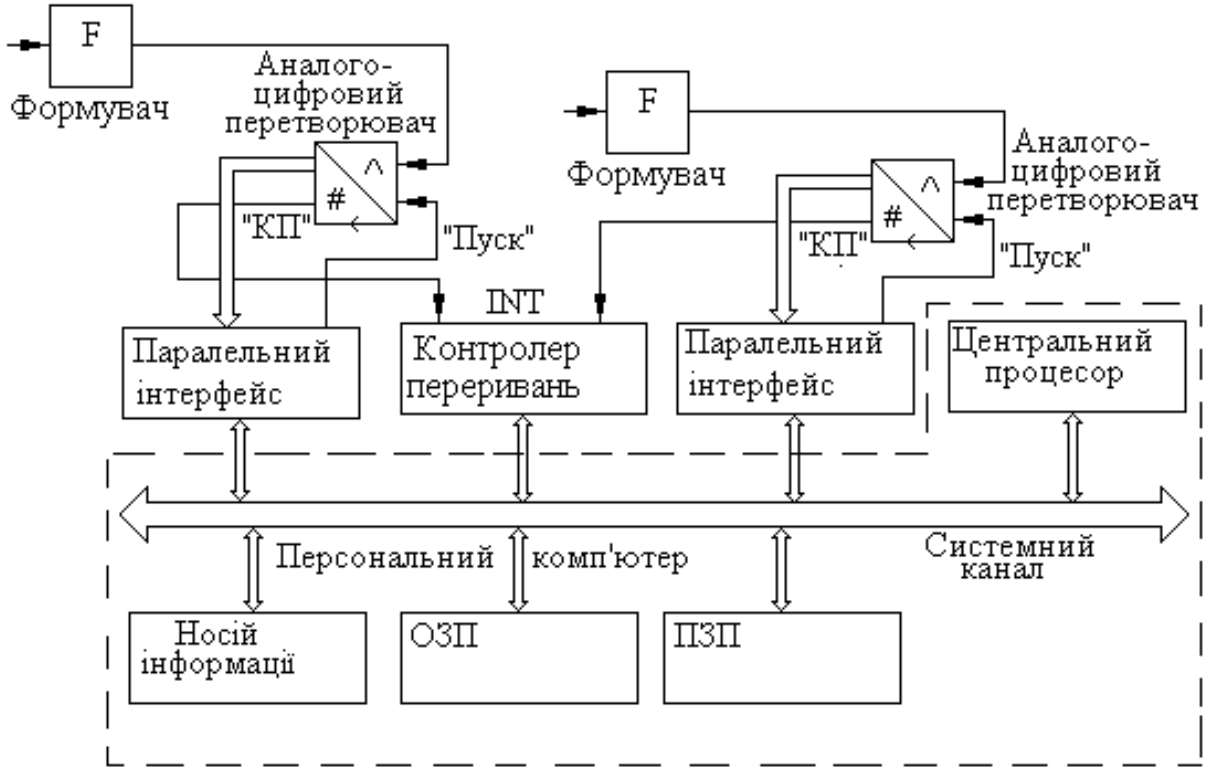

Рис. 1. Структура засобу ресстрації ЕКГ з використанням режиму переривань

Режим переривань (програмноапаратний) пов'язаний з тим, що сам обмін інформацією здійснюється в програмному режимі, а сигнали управління цим процесом формуються апаратно.

При виникненні сигналу INT, що формується зовнішнім пристроєм, центральний

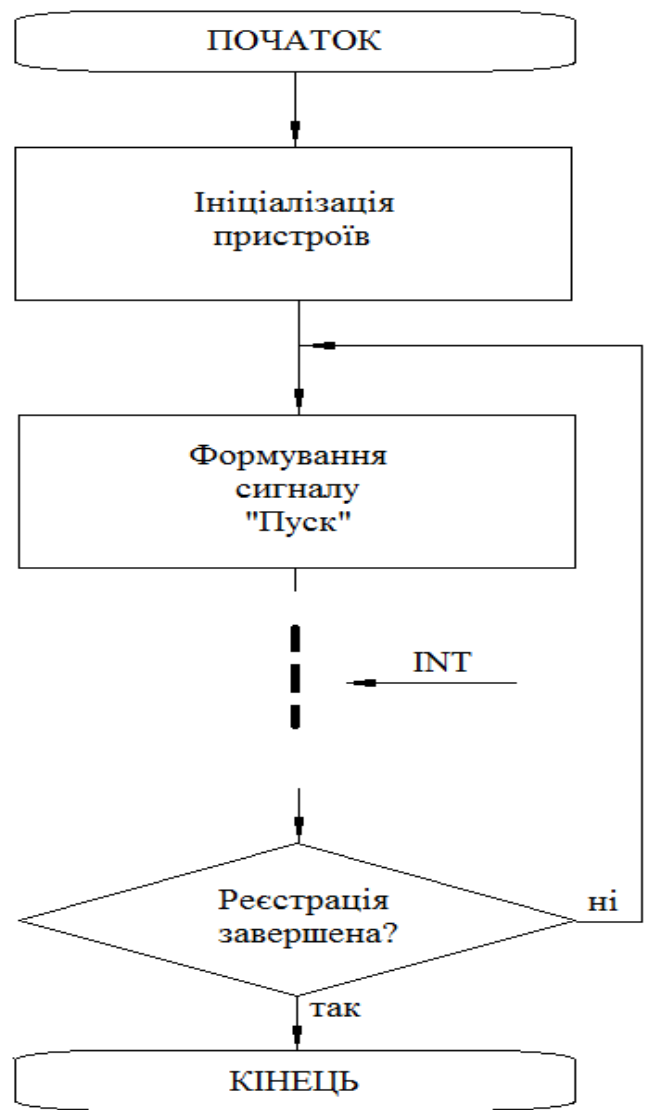

процесор закінчує виконання основної програми, всі необхідні дані фіксує в допоміжному запам'ятовувальному пристрої (стеку), і у відповідності із підпрограмою оброблювання переривання здійснює обмін даними в програмному режимі.

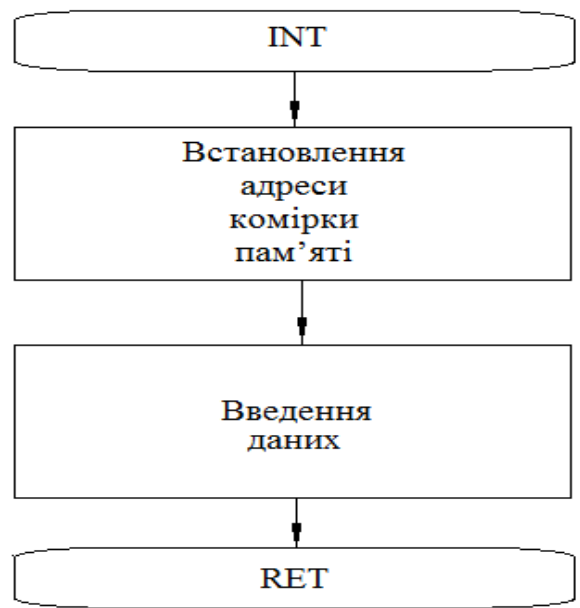

Рис. 2. Процедура ресстрації ЕКГ з використанням режиму переривань 
Після завершення підпрограми оброблювання переривання, центральний процесор зчитує зі стека раніше записані дані і повертається до виконання основної програми.

Сигнали переривання INT формуються по кожному каналу окремо і визначають область пам'яті, куди записуються дані певної ЕКГ.

Початок перетворення задається сигналом «Пуск», а завершення фіксується за сигналом «Кінець перетворення», який формує сам АЦП. Під час перетворення кодова комбінація на виході постійно змінюється і лише зчитування даних за сигналом «КП» гарантує правильність зчитаного результату. Результатом перетворення є кодова комбінація $N_{x}$, яка визначається вхідною вимірюваною напругою $U_{x}$ відповідно до формули

$$
N_{x}=\frac{U_{x}}{U_{\text {on }}} N_{\max },
$$

де $U_{\text {on }}-$ значення опорної напруги АЦП;

$N_{\max }=\left(2^{n}-1\right)-$ максимальне значення вихідного коду;

$n$ - кількість розрядів АЦП.

Тоді вимірювана напруга

$$
U_{x}=U_{\text {on }} \frac{N_{x}}{N_{\max }} .
$$

Або з урахуванням коефіцієнта перетворення формувача $k_{b x}=U_{x} / U_{B x}$

$$
U_{b x}=\frac{U_{x}}{k_{b x}}=\frac{U_{o n} \cdot N_{x}}{k_{b x} \cdot N_{\max }} .
$$

Для амплітудного вимірювального каналу похибка квантування визначається як одиниця молодшого розряду (кроку квантування), виходячи 3 чого

$$
\gamma_{A D C}=\frac{1}{N_{\max }} \cdot 100 \%=\frac{1}{2^{n}-1} \cdot 100 \% \text {. }
$$

Вираз (4) дозволяс, завдавшись похибкою, визначити необхідну кількість розрядів АЦП

$$
n=\log _{2}\left(\frac{100}{\gamma_{A D C}}+1\right) .
$$

3 урахуванням того, що кількість розря- дів АЦП має бути натуральним числом для спрощення розрахунків одиницю у формулі (5) можна опустити, округляючи результат зі збільшенням до цілого числа.

Швидкодія АЦП вибирається за похибкою дискретизації $T_{\partial}=1 / f_{\partial}$ відповідно до формул:

$$
f_{\partial}=\sqrt{\frac{x_{\max }^{\prime \prime}}{8 \gamma_{a n}}} .
$$

де $x_{\max }^{\prime \prime}$ - максимальне значення другої похідної вхідного сигналу.

$$
f_{\partial}=\sqrt[3]{\frac{x_{\max }^{\prime \prime}}{15,53 \gamma_{a n}}}
$$

$$
\begin{gathered}
\text { де } X_{\max }^{\prime \prime \prime} \text { максимальне значення третьої по- } \\
\text { хідної вхідного сигналу. }
\end{gathered}
$$

При цьому потрібно враховувати, що період дискретизації містить в собі не лише тривалість циклу перетворення АЦП, але й тривалість всіх операцій, пов'язаних із реєстрацією даних. В більшості випадків процеси в медицині та біології $є$ повільними і швидкодія сучасних АЦП є цілком достатньою.

Процедура реєстрації аналогових сигналів пов'язана із накладанням високочастотних завад.

Для їх усунення потрібно додати процедуру цифрової фільтрації [9]. В класичному випадку апроксимація всіх неперервних та дискретних сигналів здійснюється в базисі синусоїдних функцій. Для пропонованого випадку використовуються поліноміальні ортогональні функції Чебишева, тому для певного класу функцій сбіжність ряду буде значно вищою, ніж в першому випадку [10]. Функції Чебишева $T_{n}(x)$ визначаються диференціальним рівнянням

$$
T_{n}(x)=\frac{2^{n} \cdot n !}{(2 n) !} \sqrt{x^{2}-1} \frac{d^{n}}{d x^{n}}\left(\left(x^{2}-1\right)^{n-\frac{1}{2}}\right)
$$

На практиці користуються більш простими формулами для отримання ортогональних поліномів Чебишева:

$$
T_{n}(x)=\cos (n \cdot \arccos x) ;
$$




$$
T_{n+1}(x)=2 x T_{n}(x)-T_{n-1}(x),
$$

що являють собою поліноми степені $n$.

Розв'язок рівнянь (8) - (10) дозволяє отримати ряд ортогональних функцій, обмежених інтервалом $x \in[-1,1]$ і описуваних виразами (11).

$$
\begin{aligned}
& T_{0}(x)=1, \\
& T_{1}(x)=x, \\
& T_{2}(x)=3 x^{2}-1, \\
& T_{3}(x)=4 x^{3}-3 x, \\
& T_{4}(x)=8 x^{4}-8 x^{2}+1, \\
& T_{5}(x)=16 x^{5}-20 x^{3}+5 x, \\
& T_{6}(x)=32 x^{6}-48 x^{4}+18 x^{2}-1, \\
& T_{7}(x)=64 x^{7}-112 x^{5}+56 x^{3}-7 x,
\end{aligned}
$$

Краща збіжність ряду означає, що для апроксимації вихідної послідовності необхідно значно менше членів рівняння і кінцевий обсяг даних буде меншим без втрат інформації. При цьому алгоритм перетворення даних спрощується, за рахунок чого скорочується час оброблювання даних і підвищується ефективність використання процесорних засобів. На практиці обмежуються кількістю членів, які визначають 95\% енергії зареєстрованого сигналу ЕЕГ.

На рис. 3 подані результати розрахунків імовірності помилок в залежності від співвідношення сигнал/шум без фільтрації $\left(p_{k}\right)$, при класичного алгоритму фільтрації $\left(p m_{k}\right)$ та використанні поліномів Чебишева $\left(p m w_{k}\right)$.

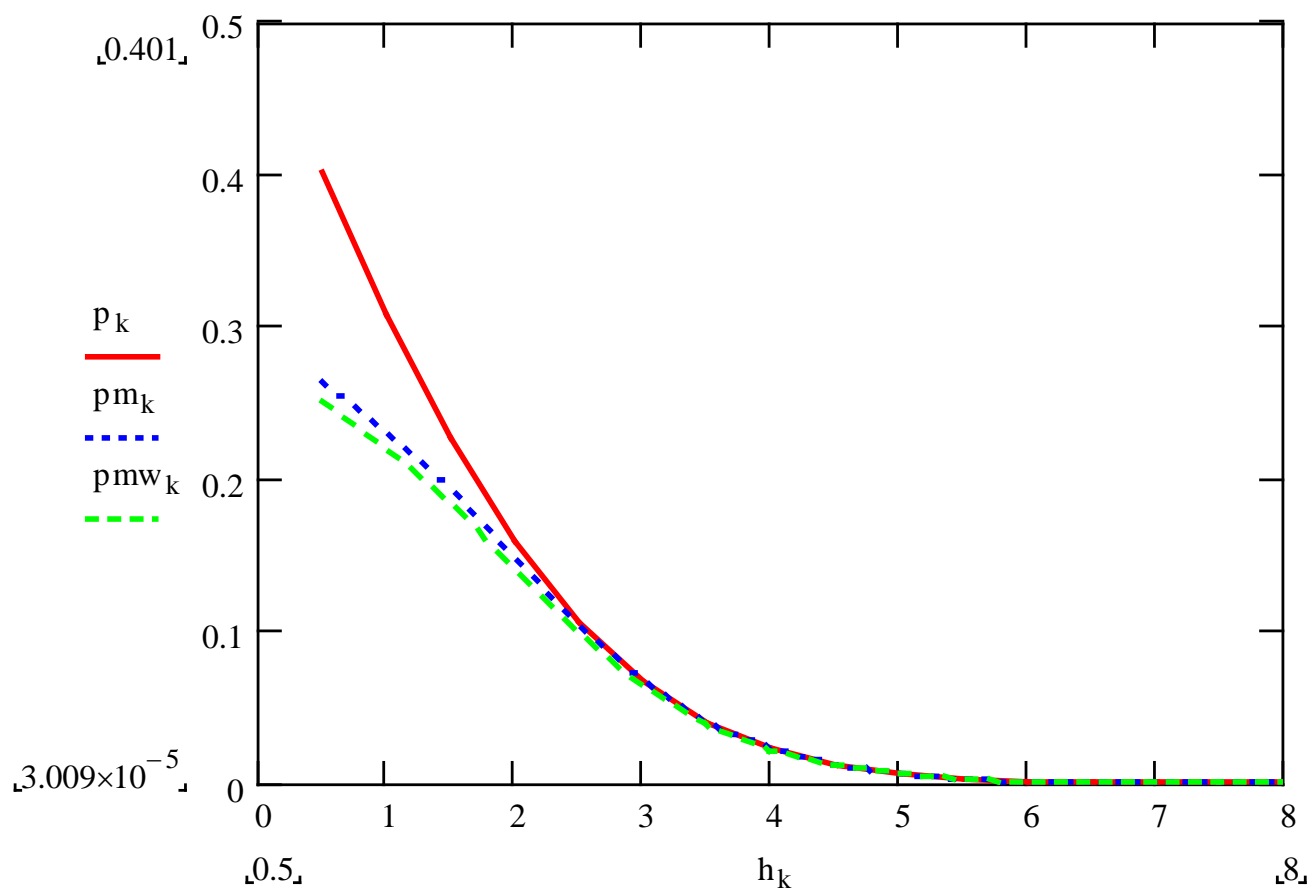

Рис. 3. Імовірності помилок в залежності від співвідношення сигнал/шум

Обсяг вибірки можна визначити цей показник за частотою виникнення події $k / n$, де $k$ - кількість дослідів $3 n$ проведених, в яких ця подія відбувалась. Цей параметр можна використати як оцінку шуканої імовірності $p$. Тобто 


$$
p\left(\frac{k}{n}<x\right)=\int_{-\infty}^{x} \frac{1}{\sqrt{2 \pi \sigma_{k / n}^{2}}} \exp \left(\frac{-\left(k / n-m_{k / n}\right)^{2}}{2 \sigma_{k / n}^{2}}\right) d k / n .
$$

При достатньо великих значеннях $n$

$$
p\left(\frac{k / n-m_{k} / n}{\sigma_{k / n}}<\frac{\Delta}{\sigma_{k / n}}\right)=F\left(\frac{n \cdot \Delta}{\sigma_{k / n}}\right) .
$$

Задаючись імовірністю $p$, можна отримати оцінку $k / n$

$$
p(k / n-p<\Delta)=t_{\Delta} \sqrt{\frac{p(1-p)}{n}},
$$

де $t_{\Delta}=\Delta / \sigma_{k / n}$.

3 імовірністю більше 0,997

$$
\Delta=3 \sqrt{\frac{p(1-p)}{n}} .
$$

Звідки

$$
n=9 \frac{p(1-p)}{\Delta^{2}}=\frac{0,027}{\Delta^{2}} .
$$

Висновки. В результаті проведених досліджень розроблено апаратне і програмне забезпечення комп'ютерної системи реєстрації ЕЕГ. Показана необхідність цифрової фільтрації і розроблений іiі алгоритм. Ефективність процедури ілюструється графіками.

\section{Список літератури}

1. Абакумов В. Г., Готра 3. Ю. Злепко С. М. та ін. Реєстрація, обробка та контроль біомедичних сигналів. Вінниця: ВНТУ, 2011. $352 \mathrm{c}$.

2. Зенков Л. Р. Клиническая электроэнцилография (с элементами эпилептологии). М.: МЕДпресс-информ, 2004. 368 с.

3. Русинов В. С. Клиническая электроэнцилография. М.: Медицина, 1987. 527 с.
4. Тодоров I. В. Електроенцилографія в психіатрії. Івано-Франківськ: Місто НВ, 2004. $76 \mathrm{c}$.

5. Жадин М. Н. Биофизические механизмы формирования электроэнцифалограммы. М.: Наука, 1984. 372 с.

6. Дорош Н. В., Кучмій Г. Л. Розробка алгоритмічної бази для мікроелектронних систем аналізу біомедичних сигналів. Вісник ДУ «Львівська політехніка». 2000. № 401. C. $65-69$.

7. Дорош Н. В., Кучмій Г. Л., Калюжна К. Р. Моделювання алгоритмів обробки електроенцефалограм для мікроелектронних систем контролю електричної активності мозку. Вісник НУ «Львівська політехніка». 2005. № 542. С. $80-84$.

8. Акулов Л. Г., Муха Ю. П. Адаптивні методи в електроенцилографічних вимірюваннях. Біомедичні технології та радіоелектроніка. 2007. № 1. С. $56-60$.

9. Кулик А. Я., Кривогубченко С. Г., Компанець М. М., Кривогубченко Д. С. Проектування мікропроцесорних засобів. Вінниця: ВДТУ, 2001. 135 с.

10. Патент 102077 України, МПК А61В 5/0476. Спосіб реєстрації електроенцефалограми / Кулик А. Я. (Україна), Власенко О. В. (Україна), Ревіна Т. Г. (Україна) та ін.; ВНМУ. - № ч 201504441; заявл. 06.05.2015, опубл. 12.10.2015, Бюл. № 19. $-6 \mathrm{c}$.

11. Овчинников П. Ф., Лисицын Б. М., Михайленко В. М. Высшая математика. К: Наука, 1989. С. 612.

\section{References}

1. Abakumov, V. G., Gotra, Z. Y., Zlepko, S. M. and other. (2011) Registration, processing and control of biomedical signals. Vinnytsya: VSTU, 352 p.

2. Zenkov, L. R. (2004) Clinical electroencephalography (with elements of epileptology) M.: MEDpress-inform, 368 p.

3. Rusinov, V. S. (1987) Clinical electroencephalography. M.: Medicina, 527 p. 
4. Todorov, I. V. (2004) Electroencephalography in psychiatry. Ivano-Frankivsk: Misto $\mathrm{NV}, 76 \mathrm{p}$.

5. Dzadin, M. N. (1984) Biophysical mechanisms of electroencephalogram formation. M.: Nauka, 372 p.

6. Dorosh, N. V., Kuchmiy, G. L. (2000) Development of algorithmic base for microelectronic systems for the analysis of biomedical signals. Bulletin of Lviv Polytechnic State University, v. 401, pp. 65 - 69.

7. Dorosh, N. V., Kuchmiy, G. L., Kalyudzna, K. P. (2005) Simulation of electroencephalogram processing algorithms for microelectronic systems for monitoring electrical activity of the brain. Bulletin of Lviv Poly- technic National University, v. 542, pp. 80 84.

8. Akulov, L. G., Muha, Y. P. (2007) Adaptive Methods in Electroencegraphy Measurements. Biomedical technologies and radio electronics, v. 1, pp. $56-60$.

9. Kulyk, A. Y., Krivogubchenko, S. G., Kompanets M. M., Krivogubchenko, D. S. (2001) Designing microprocessor tools. Vinnytsya: VSTU, $135 \mathrm{p}$.

10. UA Patent 102077. Kulyk A. Y., Vlasenko O. V., Revina T. G. and other. (2015) Method of recording an electroencephalogram.

11. Ovchinnikov, P. F., $\quad$ Lisitsin, B. M., Mihaylenko, V. M. (1989) Higher Mathematics. K: Nauka, p. 61.

A. Y. Kulyk, D.Sc., professor,

National Pirogov Memorial Medical University, Pirogov Str, 56, Vinnytsya, 21018, Ukraine, kulyk@vnmu.edu.ua

T. G. Revina,

National Pirogov Memorial Medical University, Pirogov Str, 56, Vinnytsya, 21018, Ukraine, tatiana@vnmu.edu.ua

M. V. Bodnar,

National Pirogov Memorial Medical University, Pirogov Str, 56, Vinnytsya, 21018, Ukraine, shargorod0523@gmail.com

\section{THE EEG SIGNAL REGISTRATION AND PROCESSING WITH THE USE OF CHEBYSHEV POLYNOMS}

In physiological studies, for the evaluation of brain activity, an important condition is the removal of the electroencephalogram. The article deals with the construction of a computer system for registration of EEG using the interrupt mode at the level of structure and algorithmic support. Depending on the recording technique, the system contains from three to sixteen amplitude measuring channels. An additional procedure for digital filtration using the Chebyshev polynomials is proposed for filtering of high-frequency interferences. The calculations made showed its effectiveness. The method of estimation of the minimum length of realization is offered.

Keywords: computer system, electroencifalogram, digital filtering.

Стаття надійшла 27.04.2018.

Статтю представляє А. Я. Кулик, д.т.н., професор. 